The Wilcoxon matched-pairs signed-ranks test (Siegel, 1956) was employed to evaluate statistical significance. Significant blockage of both food and water intake was observed at all brain sites following injections of the highest test concentration $(80 \mu \mathrm{g} / \mu \mathrm{l}) \quad$ of norepinephrine. At this concentration, many Ss showed no measurable food or water intake. Blockage of both feeding and drinking was also observed after injections of $40 \mu \mathrm{g} / \mu \mathrm{l}$ of norepinephrine in the preoptic area. While a marked increase in food intake was observed following injections of the lowest test concentration $(20 \mu \mathrm{g} / \mu \mathrm{l})$ of norepinephrine in the anterior hypothalamus, the increase was found to be insignificant. Injections of carbachol, at the highest test concentration $(.50 \mu \mathrm{g} / \mu \mathrm{l})$, were also effective in producing significant inhibition of feeding at both sites in the hypothalamus. In contrast, significant blockage of drinking occurred only after injections of $.25 \mu \mathrm{g} / \mu \mathrm{l}$ of carbachol in the basolateral amygdala.

\section{DISCUSSION}

The present data indicate that intracranial adrenergic and cholinergic chemical stimulation can produce depression of both feeding and drinking behavior in the cat. Injections of norepinephrine and carbachol elicit dose-response curves which generally show a decrease in ingestion as test dosage increases. Similar ingestive depression effects following injections of carbachol, but not norepinephrine, have been observed in the monkey (Sharpe, 1969). Further, it appears that the cat, unlike the rat, does not have adrenergic and cholinergic chemically coded neural systems which facilitate feeding and drinking, respectively; however, the data remain inconclusive. The nonsignificant, but facilitating, trend effects observed in some brain loci following injections of the lowest test concentration of both drugs suggest the need for additional dose-response information.

The observed appetitive depression effects contrast with results from other investigations which report that hypothalamic and limbic chemical stimulation produces no changes in ingestive behavior in the cat. It is suggested that the different findings may be due, in part, to variation in experimental procedures, such as employment of different drugs, drug concentrations, and brain loci. Further, it is possible that in similar chemical-stimulation cat studies reported in the literature, the authors were anticipating facilitation of ingestive behavior, not blockage; and, in most instances, the authors were studying other behaviors, such as sleep

and emotionality, and, subsequently, may have overlooked ingestive depression effects.

With respect to the nature of the drug's inhibitory effects on feeding and drinking behavior, at least two explanations are possible. Either test drugs acted specifically on satiation or they evoked other reactions (e.g., autonomic and emotional) which were antagonistic to ingestive behavior.

AVERY, D. D.. \& NANCE, D. M. Behavioral correlates of chemical stimulation in the cat thalamus. Psychonomic Science, 1970, 19,7-8.

BAXTER, B. L. Induction of both emotional behavior and a novel form of REM sleep by chemical stimulation applied to cat mesencephalon. Experimental Neurology, 1969, 23. 220-229.

CONNOR, J. C., ROSSI, G. V., \& BAKER, $W$. W. Analysis of the tremor induced by injection of cholinergic agents into the caudate nucleus. International Journal of Neuropharmacology, 1966, 5, 207-216. COURY, J. N. Neural correlates of food and water intake in the rat. Science, 1967, $156,1763-1765$.

FISHER, A. E., \& COURY, J. N. Cholinergic tracing of a central neural circuit underlying the thirst drive. Science, 1962, 138, 691-693.

GROSSMAN, S. P. Direct adrenergic and cholinergic stimulation of hypothalamic mechanisms. American Journal of Physiology, 1962, 202, 872-882.

GROSSMAN, S. P. Behavioral effects of chemical stimulation of the ventral amygdala. Journal of Comparative \& Physiological Psychology, 1964a, 57, 29-36.

GROSSMAN, S. P. Effects of chemical stimulation of the septal area on motivation. Journal of Comparative \& Physiological Psychology, 1964b, 58, 194-200.

\title{
Hypothalamic anticholinergic inhibition of eating and drinking in the cat
}

\author{
Worcester Foundation for Experimental Biology, Shrewbury, Mass. 01545 \\ JOEL S. MILNER † \\ Lafayette Clinic, Detroit, Mich. 48207 \\ and \\ DANIEL E. SHEER+† \\ University of Houston, Houston, Tex. 77004
}

Preoptic and anterior hypothalamic injections of three concentrations of atropine sulfate in the cat resulted in a dose-related decrease in food and water intake. Water intake was more effectively inhibited by atropine than was food intake, which was suppressed only at the highest concentration employed. Results were interpreted as being consistent with behavioral effects of hypothalamic lesions and somewhat less related to "chemically coded" behaviors in the cat.

Drinking has been elicited in water-sated rats following cholinergic injections in the hypothalamus (Grossman, 1962; Fisher \& Coury, 1962). In contrast, intrahypothalamic injections of cholinergic drugs have resulted in autonomic and emotional *NIMH Postdoctoral Fellow, Worcester Foundation for Experimental Biology.

+ Postdoctoral Fellow, Department of

Psychology, Lafayette Clinic.

++ Research supported by Air Force Contract No. 529-600-68-C-001. reactions and inhibition of eating and drinking in monkeys (Myers \& Sharpe, 1968; Sharpe, 1969) and in cats (Milner et al, 1970; Milner, 1970). Intrahypothalamic injections of anticholinergic drugs have been observed to inhibit drinking in the rat (Khavari, 1969; Block \& Fisher, 1970), but comparable data has not been reported for the cat. Thus, the present investigation tested whether or 
not cholinergic blockage in the hypothalamus of the cat can produce changes in food and water intake which are comparable to results reported for the rat.

\section{METHOD}

Six adult male and female mongrel cats, weighing $3.0 \pm 0.8 \mathrm{~kg}$, were unilaterally implanted with double-walled stainless steel cannulae in the anterior and preoptic hypothalamus. Stereotaxic coordinates for test loci were: preoptic hypothalamus (right hemisphere), $16.0 \mathrm{~mm} \mathrm{~A} \cdot \mathrm{P}, 2.0 \mathrm{~mm} \mathrm{~L},-2.0 \mathrm{~mm} \mathrm{H}$; and anterior hypothalamus (left hemisphere), $14.0 \mathrm{~mm} \mathrm{A-P,} 3.0 \mathrm{~mm} \mathrm{~L}$, -2.0 mm H (Jasper \& Ajmone-Marsan, 1954). Throughout the study, animals were individually housed and tested in stainless steel cages which measured $77 \times 45 \times 61 \mathrm{~cm}$. At the conclusion of the study, histological analysis verified the cannulae tips to be within $\pm 1.0 \mathrm{~mm}$ of the intended lateral, anterior-posterior, and horizontal planes.

The test drug, atropine sulfate, was dissolved in normal saline, and $2 \mu \mathrm{l}$ of three different concentrations, $0.625 \%, 1.250 \%$, and $2.500 \%$, were injected into the two brain areas. Chemical injections were delivered by means of a Hamilton microsyringe and micrometer manipulator, and each test injection was separated from the next by at least $48 \mathrm{~h}$. Ss were provided with Purina dry cat food and water ad lib throughout the experiment. Behavioral effects of the chemical injections were tested by comparing amount of food and water consumed during a $1-h$ preinjection baseline period with intake during a 1-h postinjection test period.

Each brain area and drug level combination was presented twice to each $S$ in a counterbalanced order. The results of the two stimulations at each concentration and brain loci were averaged for each cat.

\section{RESULTS}

Figures 1 and 2 show dose-related effects of intrahypothalamic injections of atropine sulfate on eating and drinking in the cat. The results are displayed as percentage change from baseline in food and water intakes. Statistical significance was tested by the two-tailed Walsh test (Siegel, 1956).

Cholinergic blockage in the anterior hypothalamus produced significanı inhibition of drinking at $1.250 \%$ $(p<.06)$ and $2.500 \% \quad(p<.03)$ concentrations. Food intake was significantly $(p<.03)$ affected by only the highest test concentration (2.500\%) of atropine. Similar results were found following cholinergic blockage of the preoptic hypothalamus. Atropine at $1.250 \%$ and $2.500 \%$ concentrations

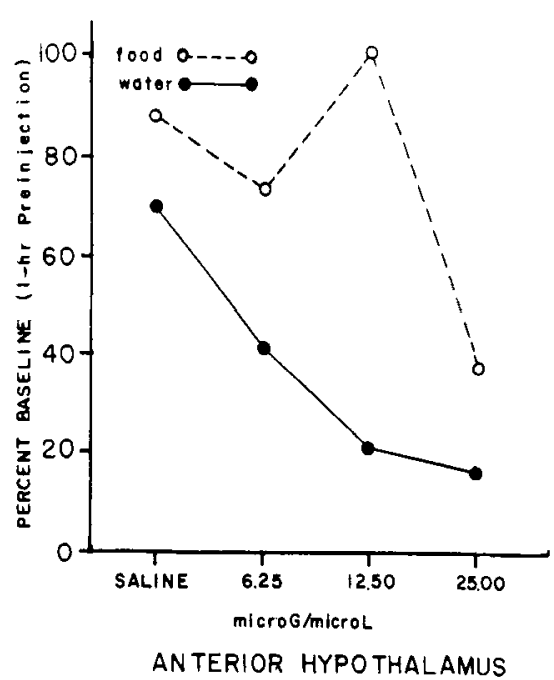

Fig. 1. Dose-related effects of anterior hypothalamic injections of atropine sulfate on eating and drinking.

produced a significant decrease in drinking $(p<.03)$. Food intake was significantly altered $(\mathrm{p}<.06)$ by only the $2.500 \%$ concentration of atropine.

\section{DISCUSSION}

Cholinergic blockage of the hypothalamus of cats results in a dose-related decrease in food and water consumption in the sated cat. However, water intake appears to be more effectively inhibited by atropine than does food intake, which was altered only by the highest concentration employed. Thus, as reported for the rat (Khavari, 1969;

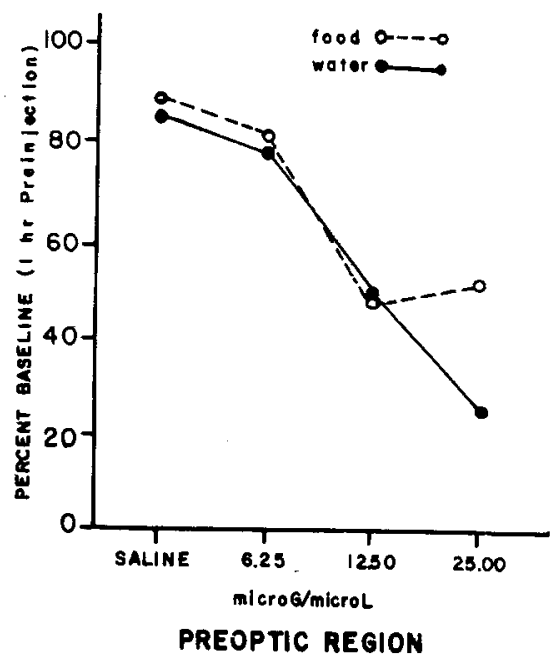

Fig. 2. Dose-related effects of preoptic hypothalamic injections of atropine sulfate on eating and drinking.
B lock \& Fisher, 1970), intrahypothalamic injections of atropine primarily affect the water intake of sated cats. However, cholinergic stimulation of the hypothalamus elicits drinking in the rat (Grossman, 1962) and inhibits drinking in the cat (Milner et al, 1970). Since cholinergic stimulation of the hypothalamus of cats also inhibits barpressing behavior (Nance, 1969), as well as producing numerous emotional and autonomic responses (Myers, 1964; Macphail \& Miller, 1968; Milner, 1970), specific inhibitory and autonomic behavioral reactions may override chemically specific ingestive behaviors. Also, a similar cholinergic circuit existing in rats and cats (Shute \& Lewis, 1966), while showing basic structural similarity, may be subserving specie-specific related behaviors. Electrolytic lesions in the hypothalamus of rats and cats produce similar changes in patterns of ingestive behavior (Anand \& Brobeck, 1951), and the present findings with "chemical lesions" is perhaps best regarded as consistent with the effects of brain lesions and somewhat less related to any specific "chemically coded" behavioral pattern in the cat.

\section{REFERENCES}

ANAND, B. K., \& BROBECK, J. $R$. Hypothalamic control of food intake in rats and cats. Yale Journal of Biology \& Medicine, 1951, 24, 123-140.

BLOCK, M. L., \& FISHER, A. E. Anticholinergic central blockade of salt-aroused and deprivation-induced drinking. Physiology \& Behavior, 1970, 5. 523-527.

FISHER, A. E., \& COURY, J. N. Chemical tracing of neural pathways mediating the thirst drive. In M. J. Wayner (Ed.), Thirst. Oxford: Pergamon Press, 1964. Pp. 515-531.

GROSSMAN, S. P. Direct adrenergic and cholinergic stimulation of hypothalamic mechanisms. American Journal of Physiology, 1962, 202, 872-882.

JASPER, H., \& AJMONE-MARSAN, C. A stereotaxic atlas of the diencephalon of the cat. Ottawa: National Research Council of Canada, 1954.

KHAVARI, K. A. Water intake of rats following unilateral and bilateral intrahypothalamic administration of atropine and scopolamine. Proceedings. 77th Annual Convention, APA, 1969. 893-894.

MacPHAIL, E. M., \& MILLER, N. E. Cholinergic brain stimulation in cats, failure to obtain sleep. Joumal of Comparative \& Physiological Psychology, $1968,65,499-503$.

MILNER, J. S., NANCE, D. M., \& SHEER, D. E. Effects of hypothalamic and amygdaloid chemical stimulation of appetitive behavior in the cat. 000000 OOO 000 OOO, in press.

MILNER, J. S. Behavioral effects of intracranial adrenergic and cholinergic chemical stimulation in the cat. Unpublished PhD thesis, Oklahoma State University, 1970.

MYERS, R. D. Emotional and autonomic response following hypothalamic chemical stimulation. Canadian Journal of Biochemistry \& Physiology, 1964, 18, 6-14. 
MYERS, R. D.. \& SHARPE, L. G. Chemical activation of ingestive and other hypothalamus regulatory mechanisms. Phvsiology \& Behavior, 1968, 3, 987-995.

NANCE, D M. Neurobehavioral correlates of intracranial chemical stimulation of the cat. Unpublished PhD thesis, Oklahoma State University, 1969.

SHARPE. L. G. Chemical stimulation of the diencephalon of the rhesus monkey (hacaca mulatta) Unpublished PhD thesis, Purdue University, 1969.

SHUTE, C. C. D., \& LEWIS, R. $P$. Cholinergic and monoaminergic pathways in the hypothalamus. British Medical Bulletin, 1966, 22, 3, 220-226.

SIEGEL, S. Nonparametric statistics for the behavioral sciences. New York: McGraw-Hill, 1956.

\title{
The specificity of social attraction in rats*
}

\author{
BIBB LATANÉ \\ The Ohio State University, Columbus, Ohio, 43210 \\ and \\ EMILY SCHNEIDER, PETER WARING, and RICHARD ZWEIGENHAFT \\ Columbia University, New York, N.Y. 10027
}

Rats housed alone or in pairs were tested daily with either the same partner or with a stranger. All rats were highly and increasingly attracted to each other, but they were not more attracted to familiar rats than to strangers. Isolated animals became more gregarious than pair-housed rats by the fourth day of testing. In Experiment 2, rats tested in trios with a stranger and a cagemate again showed no preference. The results indicate that rats do not develop specific attachments.

A series of recent studies has shown that the lowly albino rat is a highly gregarious organism. When tested in pairs in an open field, rats stay much closer to each other than would be expected by chance (Latane, 1969), or than to a variety of nonsocial objects (Latané \& Glass, 1968). With repeated testing, gregariousness increases. Typically, over $90 \%$ of all rat pairs were more affiliative on the last day of testing than on the first. In part, this is probably because exploratory

* This research was conducted at Columbia University and supported by grants from the National Science Foundation (GS 1239 and GS 2292) and the Columbia University Council for Research in the Social Sciences. Requests for reprints should be sent to Bibb Latané, Department of Psychology, The Ohio State University, $404-C$ West 17 th Avenue, Columbus, Ohio 43210 . responses, which compete with sociability in an unfamiliar environment, tend to drop out as rats become familiar with the open field (Eckman, Meltzer, \& Latané, 1969). In part, however, it may be due to the development of specific attachments between rats. It is the purpose of the present experiments to test this latter possibility.

\section{EXPERIMENT 1} Overview

Animals were housed either alone or in pairs and tested either with the same animal each day or with a stranger each day. If rats do develop specific attachments, we should expect to see cagemates more attracted to each other than to strangers, and rats tested daily with the same partner more attracted than rats tested with a different partner each day.
Subjects and Apparatus

Fifty-four naive male Sprague-Dawley rats (Carworth Farms) were 40 days old at the start of testing. They had arrived in the laboratory at 23 days of age and were housed in group cages, 12 to a cage, until they were 35 days old, at which time they were assigned randomly to new housing conditions. Food and water were always available ad lib.

Rats were tested in a circular wooden 4-ft-diam open field surrounded by an 18 -in. wall. The field was painted flat white, and the floor was marked by black lines into 49 numbered areas of equal size and equivalent shape (Latané, 1969). A $150 \cdot \mathrm{W}$ bulb was suspended $5 \mathrm{ft}$ above the center of the open field.

Experimental Conditions

Rats were assigned randomly either to isolated (14 pairs) or paired (13 pairs) housing conditions 5 days before the start of testing. Isolated animals lived alone in $10 \times 7 \times 5$ in. metal cages with wire mesh fronts and bottoms, and could thus smell and hear other rats. Paired animals lived in pairs in the same cages and thus had ample opportunity to become familiar with each other.

Within each housing condition, rats were assigned randomly either to same-partner or different-partner testing conditions. Rats in the different-partner conditions were tested with a different rat (always from the same housing condition but never their cagemate) each day, so their testing partner was always unfamiliar to them, $R$ ats in the same-partner condition were always tested with the same partner (their cagemate, if they were in the paired housing condition) each day, so they had opportunity to develop specific "friendships."

\section{Procedure}

Rats were tested $5 \mathrm{~min}$ a day for 4 consecutive days in the open field. Rats were placed in pairs in the open field, and their locations recorded at 10-sec intervals. The mean distance between the two rats over the 30 10 -sec periods was computed from the recorded locations and could range from 0 to $40 \mathrm{in}$., the lower scores indicating higher gregariousness. At the end of each trial, the field was swabbed with a damp cloth. Results

Overall, rats were quite gregarious. Every pair stayed closer together than would be expected if their movements in the open field were entirely uninfluenced by each other. Compared to a "chance" distance of about 24.8 in. (Latané, 1969), rats averaged only 16.0 in. $(p<.001) .1$

As in previous experiments, rats became more gregarious over days 